Supplement of Hydrol. Earth Syst. Sci., 21, 2405-2419, 2017

http://www.hydrol-earth-syst-sci.net/21/2405/2017/

doi:10.5194/hess-21-2405-2017-supplement

(C) Author(s) 2017. CC Attribution 3.0 License.

(c) (i)

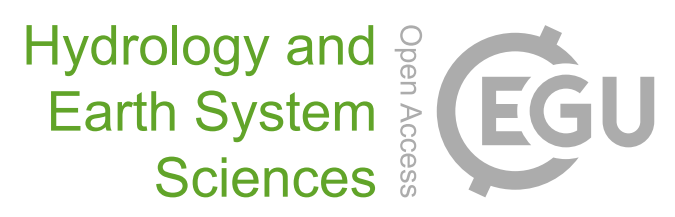

Supplement of

\title{
The spatial distribution and temporal variation of desert riparian forests and their influencing factors in the downstream Heihe River basin, China
}

Jingyi Ding et al.

Correspondence to: Wenwu Zhao (zhaoww@ bnu.edu.cn) and Lixin Wang (lxwang@iupui.edu)

The copyright of individual parts of the supplement might differ from the CC-BY 3.0 licence. 
S1 Information of sampling sites in the five classified desert riparian forest communities in the downstream Heihe River

A total of 35 sampling sites were sampled in the desert riparian forest in the downstream Heihe River. Five communities were classified by the TWINSPAN (Two-way Indicator Species Analysis). The information of sampling sites in each desert riparian forest community was shown in Table S1.

Table S1. The information of sampling sites in each desert riparian forests community.

\begin{tabular}{|c|c|c|c|c|c|c|c|c|c|}
\hline \multirow{2}{*}{ Community } & \multirow{2}{*}{$\begin{array}{r}\text { Site } \\
\text { number }\end{array}$} & \multirow{2}{*}{$\begin{array}{r}\text { Distance } \\
\text { from river } \\
\text { channel } \\
(\mathrm{m})\end{array}$} & \multirow{2}{*}{$\begin{array}{r}\text { Coverage } \\
(\%)\end{array}$} & \multicolumn{6}{|c|}{$\begin{array}{l}\text { Important value of major species in tree/shrub/herb } \\
\text { layer }\end{array}$} \\
\hline & & & & S1 & S2 & S3 & S4 & S5 & S6 \\
\hline \multirow{7}{*}{ I } & 1 & 100 & 9.00 & 1.00 & 1.00 & $\overline{-}$ & & 1.00 & - \\
\hline & 2 & $\begin{array}{l}100 \\
100\end{array}$ & $\begin{array}{l}63.38 \\
2900\end{array}$ & $1 \overline{00}$ & $1 \overline{00}$ & - & - & 1.00 & - \\
\hline & $\begin{array}{l}3 \\
4\end{array}$ & $\begin{array}{l}100 \\
100\end{array}$ & $\begin{array}{l}29.00 \\
33.17\end{array}$ & $\begin{array}{l}1.00 \\
100\end{array}$ & $\begin{array}{l}1.00 \\
1.00\end{array}$ & E & - & 062 & - \\
\hline & $\begin{array}{l}4 \\
6\end{array}$ & $\begin{array}{l}100 \\
500\end{array}$ & 80.42 & 1.00 & 1.00 & - & 二 & $\begin{array}{l}0.62 \\
1.00\end{array}$ & - \\
\hline & 7 & 500 & 41.00 & 1.00 & 1.00 & - & - & - & - \\
\hline & 15 & 1000 & 23.92 & 1.00 & 1.00 & - & - & & - \\
\hline & 21 & 2000 & 24.50 & 1.00 & & - & - & 0.51 & - \\
\hline \multirow{2}{*}{$\begin{array}{l}\text { Average } \\
\text { Value }\end{array}$} & & 550 & 38.05 & & & & & & \\
\hline & 5 & 100 & 98.67 & - & 0.88 & 0.12 & - & 0.51 & 0.11 \\
\hline \multirow[t]{2}{*}{ II } & 10 & 500 & 69.00 & - & 1.00 & & - & 0.26 & 0.10 \\
\hline & 26 & 2500 & 76.63 & - & 0.84 & 0.16 & - & 0.50 & 0.07 \\
\hline \multirow{2}{*}{$\begin{array}{l}\text { Average } \\
\text { Value }\end{array}$} & & 1033 & 81.43 & & & & & & \\
\hline & 8 & 500 & 95.00 & - & 1.00 & - & - & 0.17 & - \\
\hline & 9 & 500 & 70.00 & - & 1.00 & - & - & - & - \\
\hline \multirow[t]{3}{*}{ III } & 20 & 1500 & 78.33 & - & 1.00 & 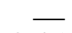 & - & - & - \\
\hline & 23 & 2000 & 55.00 & - & 0.55 & 0.45 & - & - & - \\
\hline & 25 & 2000 & 81.33 & - & 1.00 & - & - & - & - \\
\hline \multirow{2}{*}{$\begin{array}{l}\text { Average } \\
\text { Value }\end{array}$} & & 1300 & 75.93 & & & & & & \\
\hline & 12 & 1000 & 32.00 & - & 0.43 & 0.57 & - & 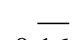 & \\
\hline \multirow{8}{*}{ IV } & 13 & 1000 & 88.79 & - & 0.44 & 0.56 & - & 0.16 & 0.23 \\
\hline & 14 & 1000 & 82.17 & - & 0.56 & 0.44 & - & 0.14 & - \\
\hline & 17 & 1500 & 81.54 & - & 0.40 & 0.60 & - & 0.38 & - \\
\hline & 18 & 1500 & 28.50 & - & 0.23 & 0.77 & - & $=$ & 一 \\
\hline & 22 & 2000 & $\begin{array}{l}41.22 \\
0823\end{array}$ & - & 0.33 & 0.67 & - & 0.65 & - \\
\hline & 24 & 2000 & $\begin{array}{l}98.33 \\
82.67\end{array}$ & - & $\begin{array}{l}1.00 \\
046\end{array}$ & 054 & - & - & 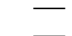 \\
\hline & 32 & 3000 & 61.35 & - & 0.32 & 0.68 & - & 0.37 & 0.20 \\
\hline & 34 & 3000 & 92.00 & - & 0.53 & 0.42 & 0.06 & & \\
\hline \multirow{2}{*}{$\begin{array}{l}\text { Average } \\
\text { Value }\end{array}$} & & 1850 & 68.86 & & & & & & \\
\hline & 11 & 1000 & 85.42 & - & 0.93 & 0.07 & - & 0.49 & 0.51 \\
\hline \multirow{8}{*}{ V } & 16 & 1500 & 52.25 & - & 0.91 & 0.09 & - & 0.19 & 0.70 \\
\hline & 19 & 1500 & 86.23 & - & 0.87 & 0.13 & - & - & \\
\hline & 28 & 2500 & 31.70 & - & 0.88 & 0.12 & - & - & 0.84 \\
\hline & 29 & 2500 & 64.83 & - & 0.61 & 0.39 & $\overline{11}$ & 一 & \\
\hline & 30 & 2500 & 23.33 & & 0.89 & & 0.11 & - & \\
\hline & 31 & 3000 & 80.50 & - & 0.64 & 0.36 & & - & 0.97 \\
\hline & 33 & 3000 & 15.54 & - & 0.38 & 0.52 & 0.10 & - & 0.87 \\
\hline & 35 & 3000 & 49.83 & - & 0.82 & 0.11 & 0.08 & - & \\
\hline $\begin{array}{l}\text { Average } \\
\text { Value }\end{array}$ & & 2278 & 54.40 & & & & & & \\
\hline
\end{tabular}

Notes: S1, Populus euphratica; S2, Tamarix ramosissima; S3, Lycium ruthenicum; S4, Reaumuria songarica; S5,

Sophora alopecuroides; S6, Karelinia caspia. Average value: the average distance from river channel and average coverage in a community. 
S2 The diurnal and annual variation of soil moisture at different soil depth in a desert riparian forest site.

Annual soil moisture data were obtained from the Environmental and Ecological Science Data Center for West China, National Natural Science Foundation of China (http://westdc.westgis.ac.cn). The monitoring site was constructed in summer 2013 in the desert riparian zone $\left(101^{\circ} 8^{\prime} 1^{\prime \prime} \mathrm{E}, 41^{\circ} 59^{\prime} 25^{\prime \prime} \mathrm{N}\right)$ (Fig.1) and the community is mainly composed of Populus euphratica and Tamarix ramosissima. We chose growing season (April to October) data series and found that variation pattern of soil moisture peaked at July in both 2014 and 2015 (Fig. S1). Therefore soil moisture in July could reflect the best water condition of the community for the whole year. Since soil moisture of the deeper layer $(20 \mathrm{~cm}-160 \mathrm{~cm})$ was relatively stable, it could represent water condition at the sampling site.
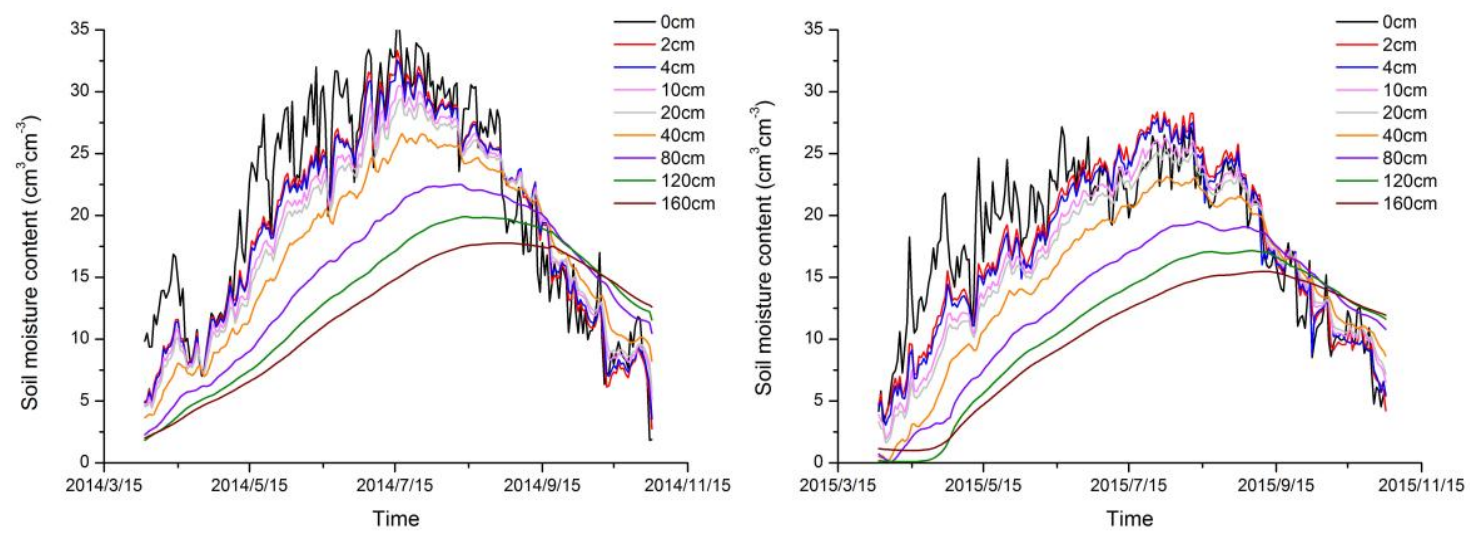

Figure S1. The intra-annual variation of soil moisture in a desert riparian forest site during the growing season in 2014 and 2015.

\section{S3 The variability of vegetation characteristic among five sampling transects.}

We sampled the community characteristics of desert riparian forest along five transects (Fig. 1). Least significant difference (LSD) test was used to determine the significance of vegetation characteristic variability among those transects (Table S2). No significant difference $(P>0.05)$ in vegetation characteristics was found among five transects, thus these five transects were treated as replicates in this manuscript. 
Table S2 Least significant difference (LSD) test for the vegetation characteristics among five transects.

\begin{tabular}{lrrrrr}
\hline & $\begin{array}{r}\text { Sum of } \\
\text { Squares }\end{array}$ & df & Mean Square & F & Sig. \\
\hline $\mathrm{H}$ & 0.035 & 4 & 0.009 & 0.131 & 0.97 \\
$\mathrm{C}$ & 0.006 & 4 & 0.001 & 0.064 & 0.992 \\
$\mathrm{R}$ & 2.64 & 4 & 0.66 & 0.736 & 0.575 \\
$\mathrm{~J}_{\text {sw }}$ & 0.059 & 4 & 0.015 & 0.189 & 0.942 \\
Height & 52.694 & 4 & 13.174 & 1.006 & 0.42 \\
Density & 0.866 & 4 & 0.216 & 0.844 & 0.508 \\
Cover-a & 1118.854 & 4 & 279.714 & 1.649 & 0.189 \\
Cover-t & 693.067 & 4 & 173.267 & 0.089 & 0.985 \\
Cover-s & 5860.857 & 4 & 1465.214 & 1.479 & 0.233 \\
Cover-h & 2281.784 & 4 & 570.446 & 0.608 & 0.66 \\
\hline
\end{tabular}

Notes: H, Shannon-Wiener diversity index; C, Simpson domination index; R, Patrick richness index; J $\mathrm{J}_{\mathrm{sw}}$, Pielou evenness index; a, total plant community; t, tree layer; s, shrub layer; h, herb layer.

\section{S4 Validation of the retrieved remote sensing data.}

Temporal variation of groundwater, $2 \mathrm{~cm}$ and $100 \mathrm{~cm}$ soil moisture were derived from West Data Center (http://heihedata.org/) as a retrieved remote sensing dataset. This dataset was generated by CLM_RIV model, a coupled model that combined the process of stream-aquifer interaction with the Community Land Model Version 4.5 (CLM4.5), using high-resolution ASTER DEM dataset, Multi-source Integrated Chinese Land Cover Map (MICLCover), Heihe Watershed Allied Telemetry Experimental Research Land Cover Map (HiWATER Land Cover Map), and the China soil characteristics dataset. The validation process of this dataset is as follows:

1) The validation result of soil moisture

The providers of the retrieved remote sensing dataset use the observation data from an automatic weather station (AWS) system in Bajitan Gobi Desert station, which is located in the middle reaches of Heihe River to validate their soil moisture simulation. Their result shows that the simulated variation pattern of soil moisture is similar to the observation. Although the simulated soil moisture has positive bias during spring and winter, this simulation can generally capture the peak value of soil moisture induced by rain events during summer. Please refer to Figure 6 (c) in Zeng et al. (2016) to see the accuracy of the simulated soil moisture compared with the observed one (www.hydrol-earth-syst-sci.net/20/2333/2016/). Since we mainly focused on the depiction of temporal variation of soil moisture during the period of vegetation growing season (summer) in our manuscript, 
these remotely-sensed soil moisture data could well reflect the temporal variation pattern of water conditions at different distances from river channel. Thus, we directly used this remote sensed soil moisture data in our study.

2) The validation result of groundwater table and the correction of simulated groundwater table in the downstream Heihe River

The providers of the retrieved remote sensing dataset use 46 observation wells that are distributed over the middle reaches of the Heihe River basin to validate the simulation of groundwater table. The validation result shows that the simulated groundwater levels are very close to the observations for most wells. However, there are still a few meters of deviation between simulated and observed levels. Please refer to Figure 7 (c) in Zeng et al. (2016) to see the accuracy of the simulated groundwater table compared with the observed one (www.hydrol-earth-syst-sci.net/20/2333/2016/). Since the simulated value (Fig. S2) was much deeper than the actual groundwater table in the downstream Heihe (Fig. S5h), we corrected the simulated groundwater table data by establishing a regression relationship between simulated and observed data along Wulantuge transect (Fig. 1) in the downstream Heihe in our study (Fig. S3). The corrected groundwater table data (Fig. S4) showed the same temporal variation pattern across different distances from river channel with the simulated data. They also showed similar groundwater table range $(2.5-3.5 \mathrm{~m})$ to the observed groundwater table (Fig. S5 h). Accordingly, we used these corrected groundwater table data to analyse the temporal variation of groundwater table (Fig. S6 c).

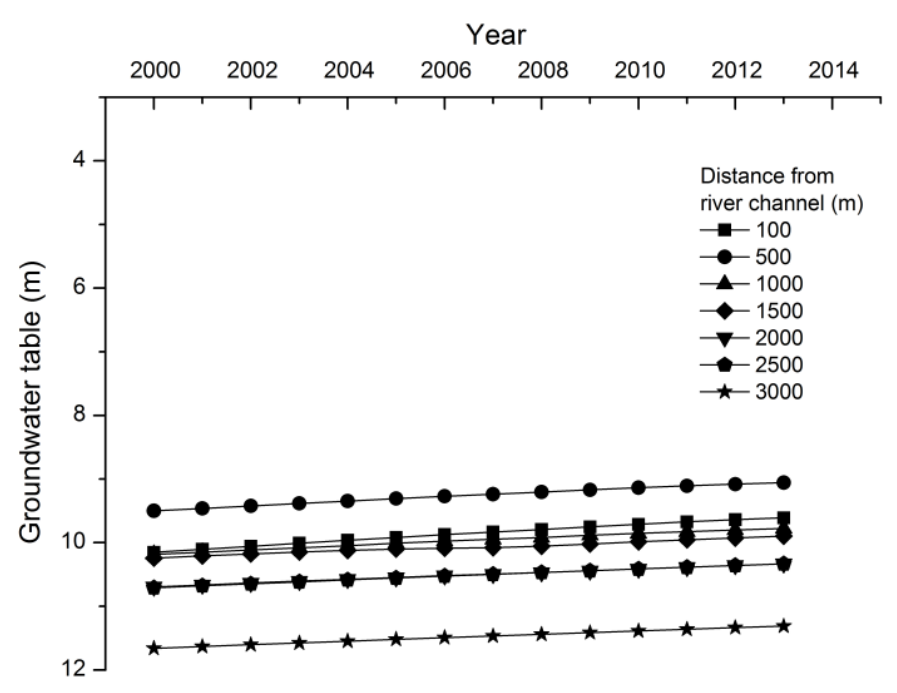

Figure S2. The variation of groundwater table during 2000-2014 at different distances from river channel derived from the retrieved remote sensing data. 


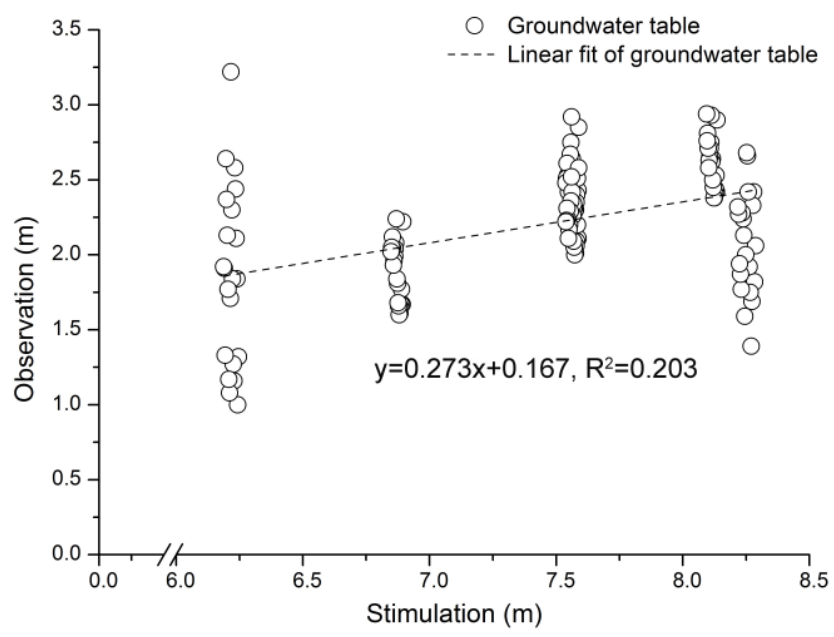

Figure S3. The linear regression between simulated groundwater table derived from the retrieved remote sensing data and observed groundwater table from the monitoring data along the Wulantuge transect in the downstream Heihe River.

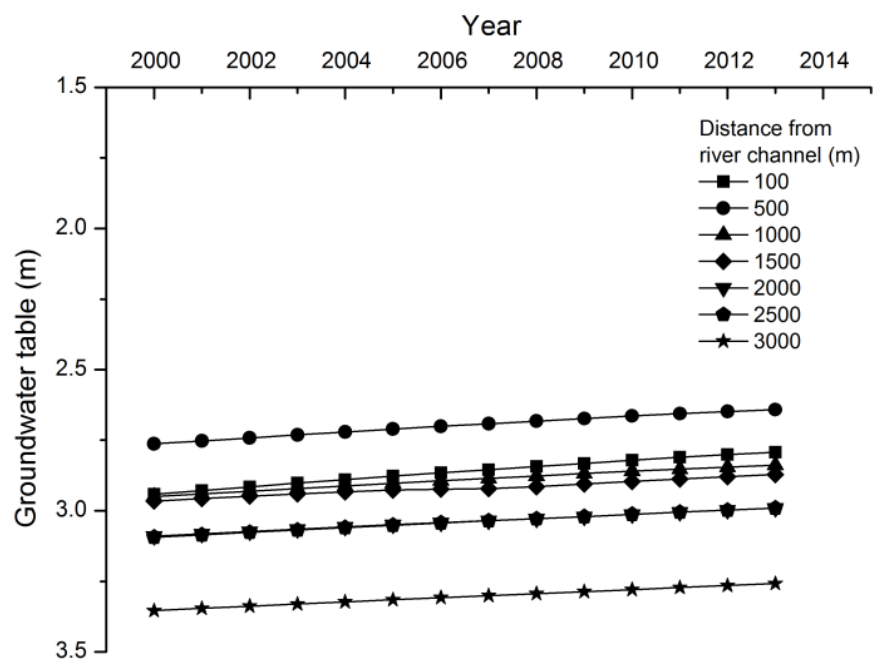

Figure S4. The variation of groundwater table during 2000-2014 at different distances from river channel based on the corrected simulated data. 


\section{S5 The spatial and temporal variation of water availability and soil properties.}

Water availability and soil properties varied significantly along the distance from the river channel (Fig. S5). SWC1 (0-30 cm soil moisture) and SWC2 (30-100 cm soil moisture) peaked at the distance of 500-1000 m and $2500 \mathrm{~m}$, following the same pattern with vegetation community coverage, and diversity indices (Fig. $4 \mathrm{c}-\mathrm{f}$ in the manuscript). SWC3 (100-200 cm soil moisture) showed a different pattern by peaking at the distance of $1000 \mathrm{~m}$ from river channel and dropped rapidly after $2500 \mathrm{~m}$ (Fig. S5 a). The proportion of silt and clay was highest at the distance of $1000 \mathrm{~m}$ from the river channel (Fig. S5 c), while bulk density reached its lowest point $\left(1.07 \mathrm{~g} \cdot \mathrm{cm}^{-3}\right)$ (Table S3). The variation of SOM, TN, TP showed the similar pattern with vegetation diversity along the distance from river channel (Fig. 4 e-g in the manuscript, Fig. S5 d-g). SOM (soil organic matter), TN (total nitrogen) and TP (total phosphorus) generally decreased along the distance from river channel and reached a relatively high value at the distances of $500 \mathrm{~m}$ and $2000-2500 \mathrm{~m}$. TS (total salt content) peaked at the distance of 1000 m (2.57\%) (Table S3) and dropped gradually. Annual average of groundwater table was $2.16 \mathrm{~m}$ deep near the river bank and leveled off at $3.27 \mathrm{~m}$ deep at the distance of 500-3000 $\mathrm{m}$ from the river channel (Table S3). 


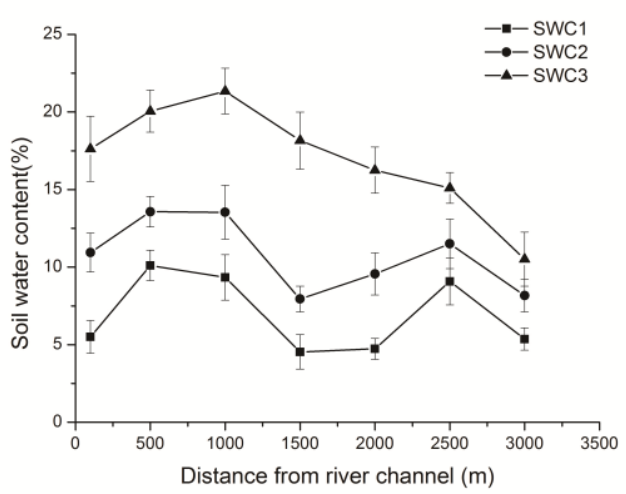

(a)

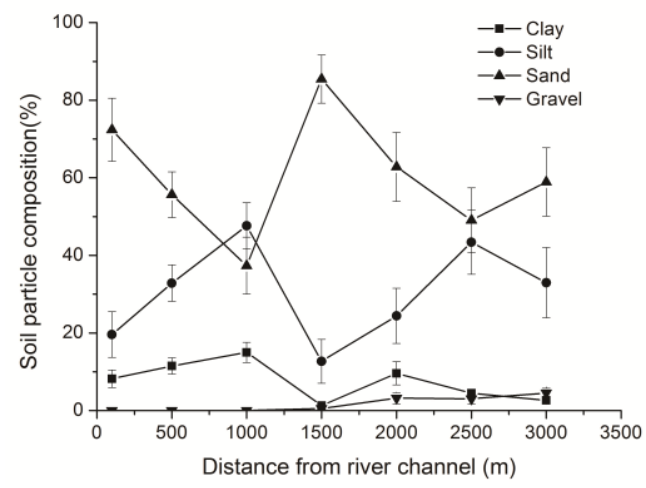

(c)

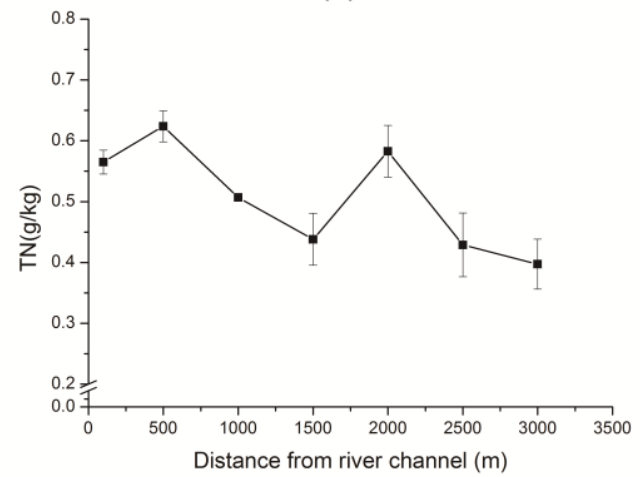

(e)

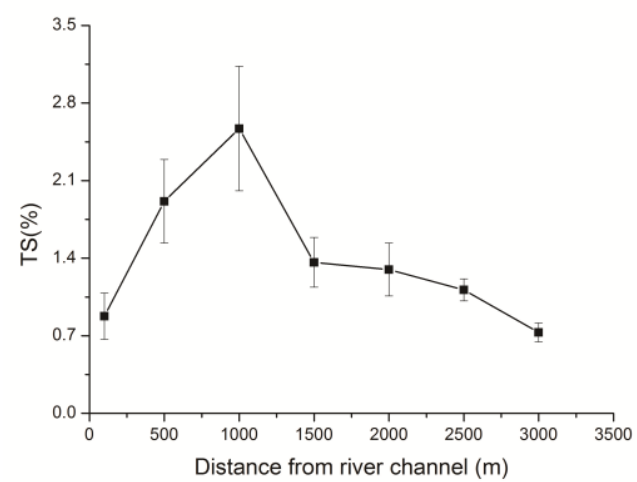

(g)

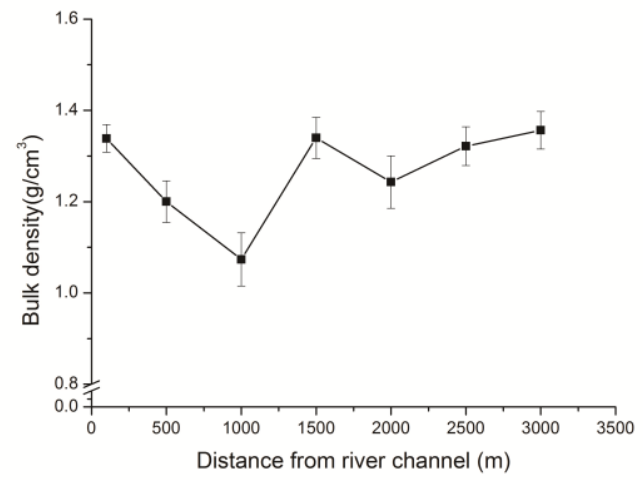

(b)

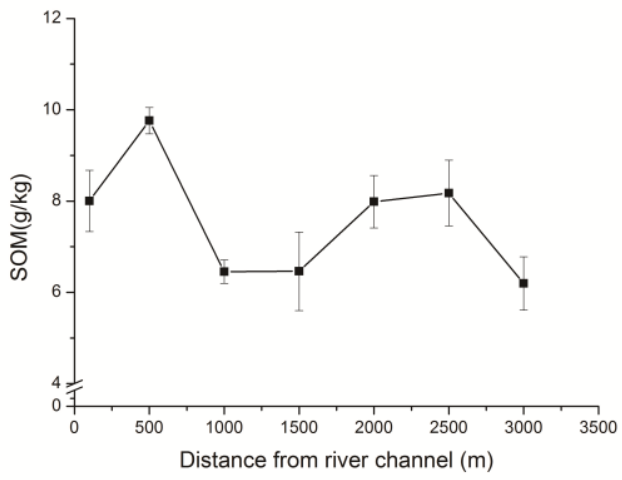

(d)

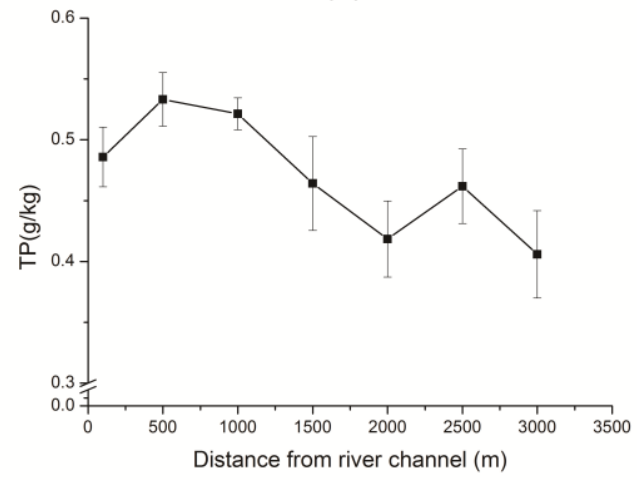

(f)

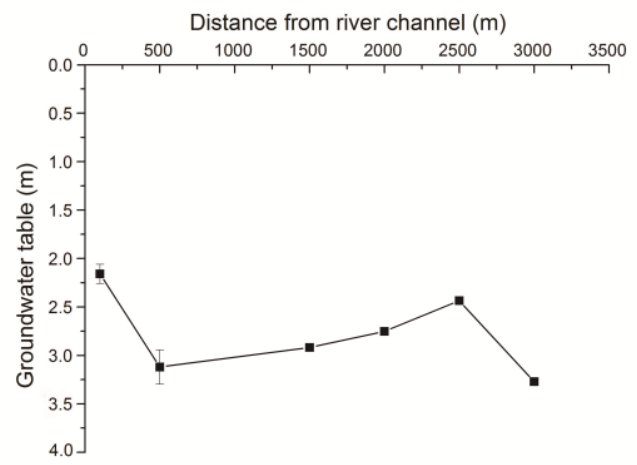

(h)

Figure S5. The variation of soil moisture (a), soil bulk density (b), soil particle composition (c), soil organic matter (d), total nitrogen (e), total phosphorus (f), total salinity (g) and groundwater (h) along the distance from river channel. 
Notes: SWC1, 0-30 cm soil moisture; SWC2, 30-100 cm soil moisture; SWC3, 100-200 cm soil moisture; BD, bulk density; SOM, soil organic matter; TN, total nitrogen; TP, total phosphorus; TS, total salt content.

Table S3 The characteristics of environmental factors at different distances from river channel.

\begin{tabular}{lrrrrrrr}
\hline Environmental & \multicolumn{7}{c}{ Distance from river channel (m) } \\
factors & 100 & 500 & 1000 & 1500 & 2000 & 2500 & 3000 \\
\hline SWC1 (\%) & $5.50 \pm 1.06$ & $10.11 \pm 0.98$ & $9.34 \pm 1.47$ & $4.54 \pm 1.12$ & $4.74 \pm 0.68$ & $9.08 \pm 1.51$ & $5.36 \pm 0.72$ \\
SWC2 (\%) & $10.94 \pm 1.25$ & $13.57 \pm 0.98$ & $13.54 \pm 1.73$ & $7.95 \pm 0.82$ & $9.56 \pm 1.36$ & $11.50 \pm 1.60$ & $8.17 \pm 1.06$ \\
SCW3 (\%) & $17.62 \pm 2.10$ & $20.05 \pm 1.36$ & $21.35 \pm 1.48$ & $18.15 \pm 1.83$ & $16.25 \pm 1.49$ & $15.11 \pm 1.00$ & $10.51 \pm 1.74$ \\
BD (g/cm3) & $1.34 \pm 0.03$ & $1.20 \pm 0.05$ & $1.07 \pm 0.06$ & $1.34 \pm 0.05$ & $1.24 \pm 0.06$ & $1.32 \pm 0.04$ & $1.36 \pm 0.04$ \\
Clay (\%) & $8.20 \pm 2.27$ & $11.50 \pm 2.08$ & $15.00 \pm 2.60$ & $1.30 \pm 0.58$ & $9.60 \pm 2.99$ & $4.50 \pm 0.84$ & $2.62 \pm 0.72$ \\
Silt (\%) & $19.60 \pm 5.88$ & $32.86 \pm 4.72$ & $47.64 \pm 5.94$ & $12.70 \pm 5.68$ & $24.40 \pm 7.10$ & $43.40 \pm 8.26$ & $32.98 \pm 9.04$ \\
Sand (\%) & $72.40 \pm 8.13$ & $55.66 \pm 5.89$ & $37.36 \pm 7.34$ & $85.46 \pm 6.21$ & $62.82 \pm 8.88$ & $49.04 \pm 8.35$ & $58.90 \pm 8.82$ \\
Gravel (\%) & 0 & 0 & 0 & $0.54 \pm 0.24$ & $3.18 \pm 1.42$ & $3.06 \pm 1.37$ & $4.52 \pm 1.27$ \\
SOM (g/kg) & $8.00 \pm 0.67$ & $9.76 \pm 0.29$ & $6.45 \pm 0.26$ & $6.46 \pm 0.86$ & $7.99 \pm 0.57$ & $8.17 \pm 0.72$ & $6.19 \pm 0.58$ \\
TN (g/kg) & $0.57 \pm 0.02$ & $0.62 \pm 0.03$ & $0.51 \pm 0.01$ & $0.44 \pm 0.04$ & $0.58 \pm 0.04$ & $0.43 \pm 0.05$ & $0.40 \pm 0.04$ \\
TP (g/kg) & $0.49 \pm 0.02$ & $0.53 \pm 0.02$ & $0.52 \pm 0.01$ & $0.46 \pm 0.04$ & $0.42 \pm 0.03$ & $0.46 \pm 0.03$ & $0.41 \pm 0.04$ \\
TS (\%) & $0.88 \pm 0.21$ & $1.91 \pm 0.38$ & $2.57 \pm 0.56$ & $1.36 \pm 0.22$ & $1.30 \pm 0.24$ & $1.11 \pm 0.10$ & $0.73 \pm 0.09$ \\
GWD (m) & $2.16 \pm 0.02$ & $2.01 \pm 0.03$ & - & $2.55 \pm 0.01$ & $2.24 \pm 0.01$ & $1.91 \pm 0.01$ & $2.66 \pm 0.01$ \\
\hline
\end{tabular}

Notes: Values represent mean \pm SE. SWC1, 0-30 cm soil moisture; SWC2, 30-100 cm soil moisture; SWC3, 100-200 cm soil moisture; BD, bulk density; SOM, soil organic matter; TN, total nitrogen; TP, total phosphorus; TS, total salt content; GWD, groundwater depth.

Temporal variations of water availability and soil properties were depicted by soil moisture, groundwater table and runoff. Soil moisture decreased with distance from the river channel and it formed an almost uniform temporal variation pattern across different distances from the river channel (Figs S6 a, b). Shallow $(2 \mathrm{~cm})$ soil moisture showed greater fluctuation than deep $(100 \mathrm{~cm})$ soil moisture (Figs S6 a, b). The depth of groundwater table increased steadily across different distances from the river channel since 2000, while the downstream runoff varied with fluctuation and increased more than doubled during the research period, from $2.07 \times 10^{8} \mathrm{~m}^{3}$ in 2000 to $5.11 \times 10^{8} \mathrm{~m}^{3}$ in 2014 (Fig. S6 d). 


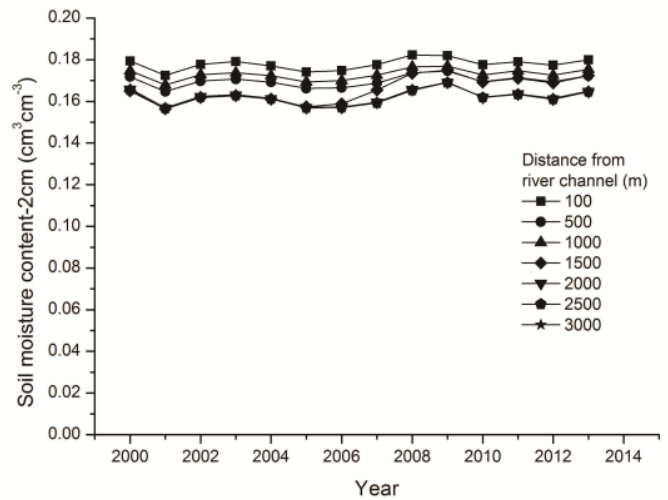

(a)

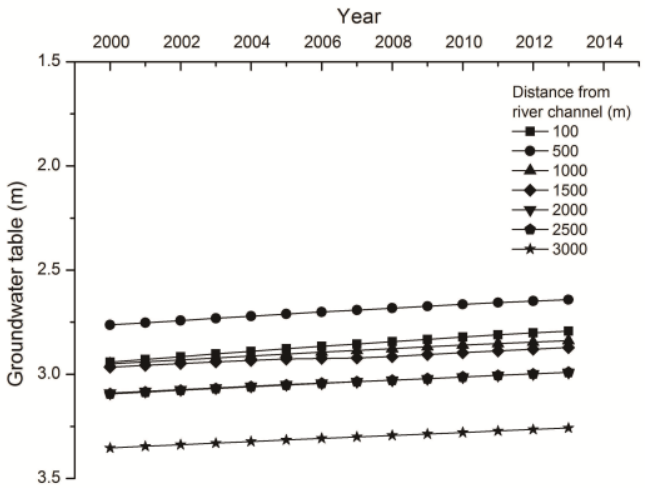

(c)

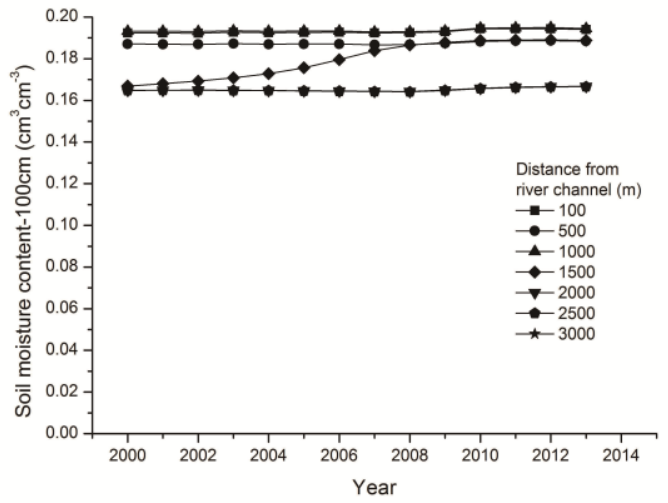

(b)

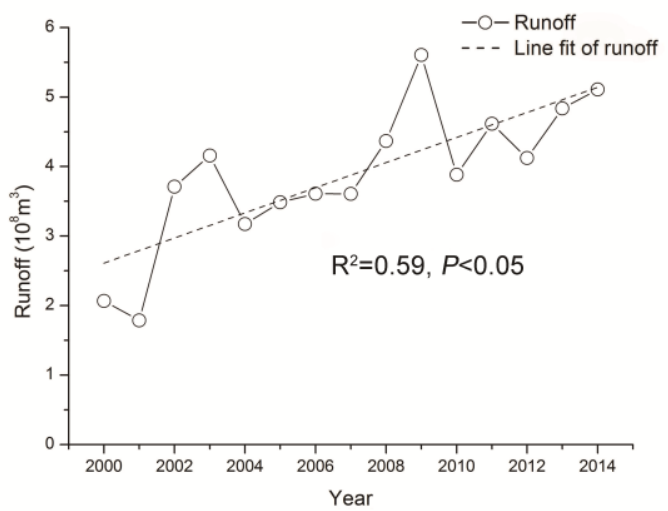

(d)

Figure S6. The variation of $2 \mathrm{~cm}$ soil moisture (a), $100 \mathrm{~cm}$ soil moisture (b), groundwater table (c), runoff (d) at different distances from river channel since 2000.

\section{S6 The sketch map explaining the meaning of a, b, $\mathrm{c}$ in Table 3.}

To further investigate the variation explained by spatial heterogeneity factors and temporal variation factors, we divided those 18 factors into two groups (i.e. "a" and "b") for partitioning analysis (Table 3 in the manuscript). Letter "a" represented spatial distribution factors, including 0-30 cm soil moisture, 30-100 cm soil moisture, 100-200 cm soil moisture, bulk density, clay, silt, sand, gravel, soil organic matter, total nitrogen, total phosphorus, total salt content. Letter "b" represented temporal factors, including annual average of $2 \mathrm{~cm}$ soil moisture, annual average of $100 \mathrm{~cm}$ soil moisture, annual variability of groundwater table, annual variability of $2 \mathrm{~cm}$ soil moisture, annual variability of $100 \mathrm{~cm}$ soil moisture. Letter "c" represented the variation that jointly explained by group "a" and "b" (Fig. S7). 


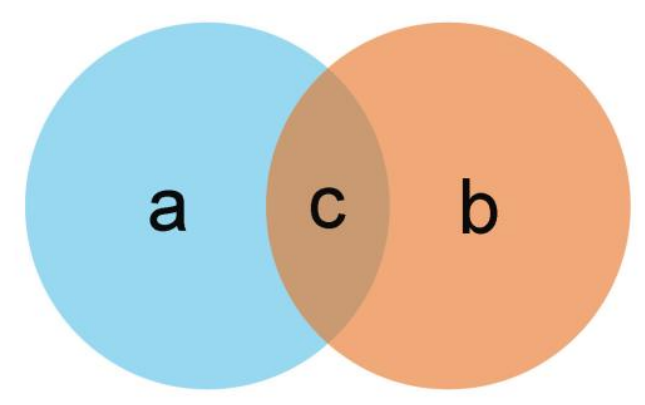

Figure S7. The sketch map of the meaning of a, b, c in Table 3.

\section{Reference:}

Zeng, Y., Xie, Z., Yu, Y., et al.: Ecohydrological effects of stream-aquifer water interaction: a case study of the Heihe River basin, northwestern China. Hydrology and Earth System Sciences, 20(6): 2333-2352, 2016, doi:10.5194/hess-20-2333-2016. 